\title{
Fever of unknown origin successfully treated by oren-gedoku-to (huanglian-jie-du-tang)
}

This article was published in the following Dove Press journal:

International Journal of General Medicine

4 October 2013

Number of times this article has been viewed

\section{Koichiro Tanaka' \\ Kazuhiko Nara' \\ Tetsuya Nishimura' \\ Keiko Serizawa' \\ Taito Miyazaki² \\ Yoshihisa Urita ${ }^{2}$ \\ Oto Miura'}

'Division of Traditional Japanese Medicine, Department of General Medicine and Emergency Care, Faculty of Medicine, Toho University, ${ }^{2}$ Department of General Medicine and Emergency Care, Faculty of Medicine,

Toho University, Tokyo, Japan
Correspondence: Koichiro Tanaka Division of Traditional Japanese Medicine, Department of General Medicine and Emergency Care, Faculty of Medicine, Toho University, 6-I I-I Omorinishi, Ota, Tokyo I43-854I, Japan

Tel $+8|337624| 5 \mid$

Fax +81337656518

Email ktanakal014@hotmail.co.jp
Abstract: Oren-gedoku-to is a traditional medicine used for treating inflammatory conditions and is given by prescription in Japan, People's Republic of China, and Korea. Its anti-inflammatory effect is related to the arachidonate cascade and inhibition of cyclo-oxygenase, but research on other anti-inflammatory pathways is ongoing. We report a case of fever of unknown origin in a 33-year-old woman. The possibility of infection due to human immunodeficiency virus, autoimmune, neoplastic, or other disease was examined and excluded. Oren-gedoku-to was successfully used to treat her symptoms and may thus be a suitable treatment for patients with undiagnosed fever of unknown origin.

Keywords: fever of unknown origin, oren-gedoku-to, huanglian-jie-du-tang, kampo

\section{Introduction}

Despite advances in diagnostic techniques, fever of unknown origin (FUO) remains a formidable challenge, with the cause of fever not being identified in $7 \%-38 \%$ of patients. ${ }^{1}$ Oren-gedoku-to (OGT) has been used traditionally to remove "heat" and "poison" from the body. ${ }^{2}$ On the basis of this theory in Oriental medicine, it has been used in clinical practice to treat inflammation, hypertension, gastrointestinal disorders, and liver and cerebrovascular disease. ${ }^{2}$ In Japan, OGT is manufactured as a powdered, freeze-dried water extract by Tsumura Co, Ltd (Tokyo, Japan).

\section{Case report}

A 33-year-old woman was admitted to our general medicine department with FUO which had persisted for longer than 2 months and was resistant to treatment with nonsteroidal anti-inflammatory drugs and prednisolone $20 \mathrm{mg} /$ day. Her fever was remittent, and body temperature ranged from $37.5^{\circ} \mathrm{C}$ to $38.5^{\circ} \mathrm{C}$. She reported sweating and headache, but did not complain of body weight change, pain, nausea, abnormal vaginal bleeding, or diarrhea.

To treat dysmenorrhea and premenstrual syndrome, she had been prescribed oral contraceptives (levonorgestrel, ethinylestradiol) for 7 years, and the dose had remained unchanged during that period. She had no history of pregnancy, and a gynecologic examination revealed no infectious or malignant findings.

She had been receiving regular follow-up care for mild depression for 3 years at our department of psychiatry and had been prescribed the antidepressants, aripiprazole and duloxetine hydrochloride, until 2 months before admission. Her depressive symptoms were stable upon presentation to our department. She had asthma, which 
was well controlled with the inhaled steroid budesonide (200 $\mu \mathrm{g}$, once daily).

She was a housewife and only had sexual contact with her husband, who had no sexually transmitted diseases. She had no pets and no animal or insect bites. She had not traveled for one year and had no history of drug abuse. A family history revealed no hereditary cause of fever.

Her height was $152 \mathrm{~cm}$ and body weight was $56 \mathrm{~kg}$. Her mental status was alert, and blood pressure was $92 / 60 \mathrm{mmHg}$ in a sitting position. Although the rise in body temperature was accompanied by an increase in pulse rate, her pulse was normal, ranging from 58 to 82 beats per minute. Her pulse rate was regular in rhythm, and its size, and tension were within the normal ranges. Her body temperature was $38.5^{\circ} \mathrm{C}$ and her respiratory rate was 15 per minute. Physical examination revealed no abnormalities, such as focal inflammation, lymph node swelling, skin rash, or abnormal heart sounds.

Laboratory analysis showed no biological inflammation C-reactive protein $0.0 \mathrm{mg} / \mathrm{L}$, and interleukin-6 $(2.1 \mathrm{pg} / \mathrm{mL}$, normal range $<4.0 \mathrm{pg} / \mathrm{mL}$ ) and tumor necrosis factor- $\alpha$ $(0.6 \mathrm{pg} / \mathrm{mL}$, normal range $0.6-2.8 \mathrm{pg} / \mathrm{mL})$ were normal. A chest X-ray showed no abnormal findings, and sputum culture for acid-fast bacteria was negative. In addition, an interferon- $\gamma$ release assay (QFT-2G, Oxford Immunotec Co, Ltd, Oxford, UK) was not positive $(0.30 \mathrm{IU} / \mathrm{L}$, normal range $<0.80 \mathrm{IU} / \mathrm{L}$ ). The results for the remaining biological tests were all in the normal ranges, as shown in Table 1. Contrast thoracic and abdominal computed tomography, brain magnetic resonance imaging, and gallium scintigraphy excluded infection, including tuberculosis, and rheumatic/inflammatory, neoplastic, or other focal abnormalities.

Fever decreased 2 days after adding Yokukan-san to $7.5 \mathrm{~g}$ of powdered OGT, which is the standard dose for

Table I Laboratory findings

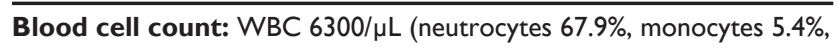
eosinocytes $1.3 \%$, lymphocytes $25.2 \%$ )

Biochemistry: CRP $0.1 \mathrm{mg} / \mathrm{L}, \mathrm{BUN} 12 \mathrm{mg} / \mathrm{dL}, \mathrm{Cr} 0.1 \mathrm{mg} / \mathrm{dL}$,

AST I 4 IU/L, ALT 8 IU/L, LDH 20 I U/L

Serology: rheumatoid factor $<5 \mathrm{IU} / \mathrm{mL}(<20)$, anti-nuclear antibody 40 index $(<40)$, interferon- $\gamma 0.30 \mathrm{IU} / \mathrm{L}(<0.80)$, interleukin-6, $2.1 \mathrm{pg} /$ $\mathrm{mL}(<4.0), \mathrm{TNF}-\alpha 0.6 \mathrm{pg} / \mathrm{mL}(0.6-2.8), \mathrm{P}-\mathrm{ANCA}<5 \mathrm{IU} / \mathrm{mL}(<20)$, C-ANCA $<5 \mathrm{IU} / \mathrm{mL}(<20)$, ferritin $12.6 \mathrm{ng} / \mathrm{mL}(10-80)$

Urine: WBC-negative

Blood culture: negative

Sputum culture: normal bacterial flora, acid-fast bacterium-negative

Note: (), normal range.

Abbreviations: WBC, white blood cells, CRP, C-reactive protein, TNF, tumor necrosis factor; P-ANCA, perinuclear anti-neutrophil cytoplasmic antibody; C-ANCA, cytoplasmic anti-neutrophil cytoplasmic antibody. adults (Figure 1). OGT was then prescribed for an additional 10 days, and fever has not relapsed after a follow-up period of 2 months.

\section{Discussion}

FUO is defined as a fever $>38.3^{\circ} \mathrm{C}$ on several occasions, during a period of at least 3 weeks, that remains undiagnosed after one week of investigation. ${ }^{3}$ After considering the four categories of FUO, ie, classical, neutropenic, nosocomial, and human immunodeficiency virus-associated fever, this patient met the criteria for classical FUO, ${ }^{4,5}$ An evidencebased approach divides FUO into four general categories, ie, infectious, autoimmune, neoplastic, and miscellaneous diseases, each of which requires certain investigations to be performed. ${ }^{6}$

A complete history, physical assessment, and laboratory testing revealed no diagnostic clues. Among the infectious diseases associated with FUO, tuberculosis is the most common in Japan. However, a chest X-ray did not show abnormal findings, and sputum culture for acid-fast bacteria was negative. In addition, an interferon- $\gamma$ release assay was not positive. Tuberculosis was thus excluded. Among the autoimmune diseases associated with FUO, rheumatoid factor, antinuclear antibody, antineutrophil cytoplasmic antibody, and ferritin were negative. Regarding malignancy, contrast thoracic and abdominal computed tomography, brain magnetic resonance imaging, and gallium scintigraphy excluded nonhematologic malignancies. Results of a peripheral blood smear were also within normal ranges.

Drug fever was also considered. Inhaled steroid therapy for asthma was the same before and after admission. Use of aripiprazole and duloxetine hydrochloride had been stopped 2 months before admission. During that 2-month period, she did not report stress in her environment, and her mental condition remained stable. Antidepressant therapy was thus excluded as the cause of fever. The effects of oral contraceptives (levonorgestrel, ethinylestradiol) on fever were also considered. She had been prescribed oral contraceptives for 7 years, and the dose remained unchanged during that period. She reported sweating and headache but no other side effects of oral contraceptives, such as body weight change, pain, nausea, and abnormal vaginal bleeding. Fever due to oral contraceptives is usually low-grade, unlike the continuous high fever in this case. Therefore, oral contraceptive use was not considered the cause of fever. Patients with chronic fatigue syndrome can also have low-grade FUO. However, they usually complain of muscle weakness, myalgia, arthralgia, or chills. Our patient had no such complaints. ${ }^{7}$ 


\section{Degree}

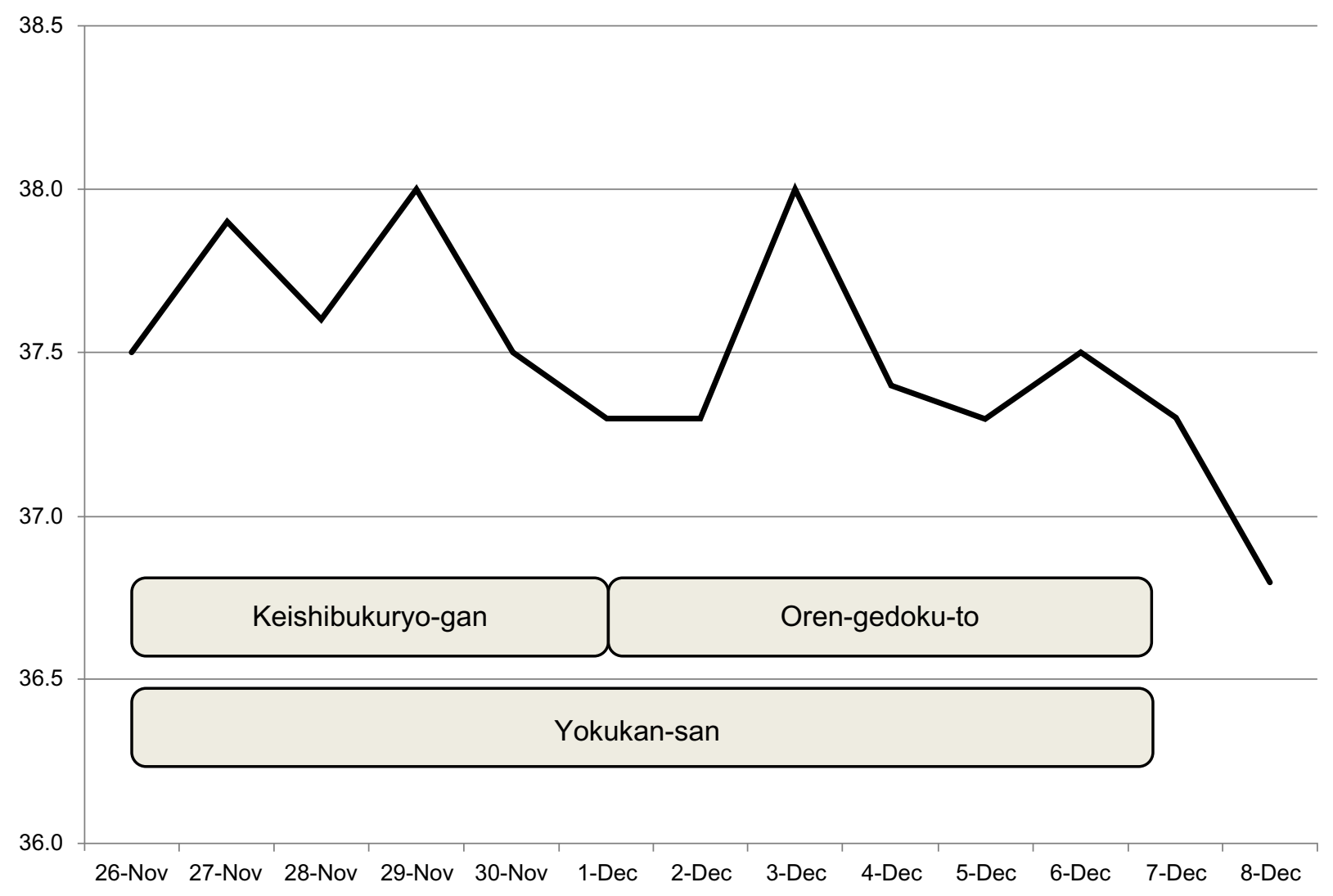

Figure I Body temperature during treatment.

OGT has been used for 2,000 years to remove "heat" and "poison" from the body. ${ }^{2}$ With the development of modern medicine, "heat" and "poison" have come to be considered aspects of inflammation, hypertension, gastrointestinal tract disorders, and liver and cerebrovascular disease, which are indications for OGT. ${ }^{2}$ OGT is contraindicated for patients who are sensitive to cold.

OGT comprises four decocted medicinal herbs (g): Rhizoma coptidis (2.0), Radix scutellariae (3.0), Cortex phellodendri (2.0), and Fructus gardeniae (1.5). R. scutellariae has the active ingredients baicalin, baicalein, and wogonin, which suppress the arachidonate cascade by inhibiting cyclo-oxygenase (COX)-2, 5-lipoxygenase, but not COX-1, in rats and mice. ${ }^{8,9}$ Moreover, OGT has an inhibitory effect on free radical production: baicalin, baicalein, and wogonin suppressed lipopolysaccharide-induced nitric oxide, wogonin suppressed lipopolysaccharide-induced COX-2, and OGT directly protected red blood cell membranes from free radical damage. ${ }^{9,10}$ The four decocted medicinal herbs have been shown to have greater anti-inflammatory effects than each herb used alone. ${ }^{11,12}$ In our patient, C-reactive protein, interferon- $\gamma$, and inflammatory cytokines, such as interleukin- 6 and tumor necrosis factor- $\alpha$, were within normal ranges. In future cases, interleukin- 8 , a leukocyte chemotactic factor, should also be measured, to understand better the anti-inflammatory action of OGT. Although the multiple anti-inflammatory effects of OGT are under investigation, the present results suggest that OGT might be an effective agent for FUO, because its anti-inflammatory effects do not depend only on the arachidonate cascade.

It should be stressed, however, that this is a report of only one case. Nevertheless, our findings indicate that OGT is a possible treatment for FUO that remains undiagnosed after an extensive diagnostic workup.

\section{Conclusion}

OGT is a possible treatment for FUO, after exclusion of infectious, rheumatic/inflammatory, neoplastic, and other diseases. In addition, the anti-inflammatory effects of OGT that depend on pathways other than the arachidonate cascade should be investigated in future studies.

\section{Disclosure}

The authors report no conflict of interests in this work. 


\section{References}

1. Arnow PM, Flaherty JP. Fever of unknown origin. Lancet. 1997;350: 575-580.

2. Oshima N, Narukawa Y, Hada N, Kiuchi F. Quantitative analysis of antiinflammatory activity of orengedokuto: importance of combination of flavonoids in inhibition of PGE2 production in mouse macrophage-like cell line J774.1. J Nat Med. 2013;67:281-288.

3. Petersdorf RG, Beeson PB. Fever of unexplained origin: report on 100 cases. Medicine. 1961;40:1-30.

4. Knockaert DC, Vanderschueren S, Blockmans D. Fever of unknown origin in adults: 40 years on. J Intern Med. 2003;253:263-275.

5. Durak DT, Street AC. Fever of unknown origin - reexamined and redefined. Curr Clin Top Infect Dis. 1991;11:35-51.

6. Mourad O, Palda V, Detsky AS. A comprehensive evidence-based approach to fever of unknown origin. Arch Intern Med. 2003;163: 545-551.

7. Oka T, Oka K. Age and gender differences of psychogenic fever: a review of the Japanese literature. Biopsychosoc Med. 2007;1:11.

8. Fukutake M, Miura N, Yamamoto M, et al. Suppressive effect of the herbal medicine Orengedoku-to on cyclooxygenase-2 activity and azoxymethane-induced aberrant crypt foci development in rats. Cancer Lett. 2000;157:9-14.
9. Chen YC, Shen SC, Chen LG, Lee TJ, Yang LL. Wogonin, baicalin, and baicalein inhibition of inducible nitric oxide synthase and cyclooxygenase-2 gene expressions induced by nitric oxide synthase inhibitors and lipopolysaccharide. Biochem Pharmacol. 2001;61: 1417-1427.

10. Sekiya N, Shibahara N, Sakakibara I, Hattori N, Goto H, Terasawa K. Inhibitory effects of Oren-Gedoku-To (Huanglian-Jie-Du-Tang) on free radical-induced lysis of human red blood cells. Phytother Res. 2003;17: $147-151$.

11. Lu J, Wang JS, Kong LY. Anti-inflammatory effects of HuangLian-Jie-Du decoction, its two fractions and four typical compounds. J Ethnopharmacol. 2011;134:911-918.

12. Okamoto H, Chino A, Hirasaki Y, Ueda K, Iyo M, Namiki T. Orengedoku-to augmentation in cases showing partial response to yokukan-san treatment: a case report and literature review of the evidence for use of these Kampo herbal formulae. Neuropsychiatr Dis Treat. 2013;9:151-155.

\section{Publish your work in this journal}

The International Journal of General Medicine is an international, peer-reviewed open-access journal that focuses on general and internal medicine, pathogenesis, epidemiology, diagnosis, monitoring and treatment protocols. The journal is characterized by the rapid reporting of reviews, original research and clinical studies across all disease areas.
A key focus is the elucidation of disease processes and management protocols resulting in improved outcomes for the patient.The manuscript management system is completely online and includes a very quick and fair peer-review system. Visit http://www.dovepress.com/ testimonials.php to read real quotes from published authors. 